\title{
THE RELATION BETWEEN BIRTH WEIGHT AND SUBSEQUENT WEIGHT IN CHILDHOOD
}

\author{
BY \\ G. HERDAN \\ From the Department of Preventive Medicine, University of Bristol
}

(RECEIVED FOR PUBLICATION JANUARY 7, 1954)

The most recent investigations of the relation of birth weight to subsequent weight (Illingworth, 1950; Illingworth, Harvey and Gin, 1949) have led to the conclusion 'that the birth weight had a constant and very important relationship to subsequent weight at all ages studied (up to 13 years)'. This is an important matter in paediatrics because many assessments of children's growth are based on it. It is therefore essential for the correct interpretation of the result to ascertain whether a generalization as expressed above is justified and, if not, to show in what respects it must be qualified if it is to serve as a useful criterion for judging children's growth. As will be shown, the statement requires qualification in three respects: (1) as regards the extent or intensity of the dependence of subsequent weight on birth weight; (2) as regards the supposed constancy of the relation throughout childhood; and (3) as regards the meaning of such a dependence. To each of these items, one of the following sections is devoted.

\section{Dependence of Subsequent Weight on Birth Weight}

In the first paper quoted the growth of children from 4 to 13 years was investigated, in the second that of children up to 3 years. The conclusions therefore apply to all ages of childhood up to 13 years. In amplified form the conclusions reached are as follows. 'Throughout childhood the average child who was a small baby at birth weighs considerably less than the average child who at birth was a large baby'... 'The same gradation of weight in relation to birth weight was shown in all the age groups studied' (Illingworth, 1950).

These conclusions are based upon a comparison of averages, as can be seen from Table 1, and also of ranges, without, however, considering the effect which the extent of the range must have upon the supposedly close correlation between birth weight and subsequent weight. The comparison in Table 1 is between the average subsequent weights of children who belong to different birth weight classes. Admittedly, there appears to be a tendency of subsequent weights at a given age to parallel the difference in birth weight, though no attempt is made to determine whether differences between the birth weight groups in that respect, which are sometimes very small, are really significant.

TABLE 1

RELATION OF BIRTH WEIGHT TO AVERAGE SUBSEQUENT WEIGHT (ILLINGWORTH, 1950)

\begin{tabular}{|c|c|c|c|c|c|}
\hline & $\begin{array}{l}\text { Group A } \\
\text { (5 lb. } 8 \text { oz. } \\
\text { or less) }\end{array}$ & & $\begin{array}{l}2 \text { o B } \\
2 \text { oz.- } \\
6 \text { oz.) }\end{array}$ & $\begin{array}{c}\text { Group C }{ }^{-} \\
\text {(8 lb. } 8 \text { oz.- } \\
9 \text { lb. } 7 \text { oz. })\end{array}$ & \\
\hline \multirow[b]{2}{*}{ 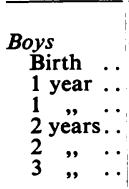 } & lb. oz. & lb. & oz. & lb. oz. & lb. oz. \\
\hline & $\begin{array}{rrr}4 & 14 & \\
20 & 12 & (51)^{*} \\
22 & 6 & (18) \\
24 & 3 & (26) \\
28 & 0 & (10) \\
28 & 9 & (10)\end{array}$ & $\begin{array}{l}7 \\
22 \\
26 \\
26\end{array}$ & $\begin{array}{l}4 \\
5 \text { (36) } \\
2 \text { (23) } \\
8 \text { (26) } \\
=\end{array}$ & 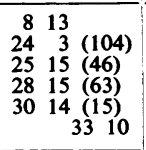 & $\begin{array}{|ccc|}9 & 15 \\
24 & 7 & (44) \\
27 & 2 & (22) \\
29 & 1 & (22) \\
30 & 11 \\
(18) \dagger & (10) \\
(18) & \end{array}$ \\
\hline $\begin{array}{l}\text { Birth } \\
1 \text { year } \\
1 \text {," } \\
2 \text { years } \\
3 \text { ", }\end{array}$ & $\begin{array}{rrr}5 & 0 & \\
19 & 11 & (59) \\
21 & 15 & (23) \\
24 & 12 & (31) \\
28 & 1 & (15)\end{array}$ & $\begin{array}{l}7 \\
21 \\
24 \\
27\end{array}$ & $\begin{array}{r}4 \\
13(48) \\
13(15) \\
0(28) \\
-\end{array}$ & 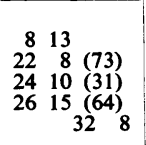 & $\begin{array}{rrr}9 & 14 & \\
23 & 3 & (23) \\
25 & 4 & 9) \\
29 & 9 & (19) \\
(20) \dagger & \end{array}$ \\
\hline
\end{tabular}

* The figures in parenthesis indicate the number of children in each group.

$\dagger$ Groups $\mathbf{C}$ and $\mathbf{D}$ are combined owing to smallness of numbers.

The point, however, which we wish to make here is that the comparison by means of averages, or ranges, is not satisfactory if it leaves out the adverse effect which the spread of subsequent weight around the mean, and the extent of overlap between birth weight categories in this respect, has upon the dependence of subsequent weight upon birth weight. To know this is essential because there is no such thing in nature as the 'average' child. This is a mathematical construction, and all we have before us is individual children and therefore individual weights. It is now just the subsequent weight of the individual child which is to be regarded in the light of its dependence upon the birth weight. If 
one wishes to allay a mother's worry about her child being underweight for its age, by going back to the child's low birth weight as a sufficient explanation, then it is clearly not the average but the individual child one is concerned with, and the probable deviation of the individual child's weight from what is expected for the average child must not be forgotten.

The correct method for determining the dependence of subsequent weight upon birth weight is that of correlation analysis. Such an analysis was carried out for 3-year-old children by Lowe and Gibson (1953). The authors arrived at a correlation coefficient of $\cdot 49$ for males and $\cdot 50$ for females. The meaning of the correlation is this. It gives an overall idea of how much the variation of one variable is due to the variation in the other. In our case, it means how much of the variation in the subsequent weight, that is at 3 years of age, is due to the variation in the weight at birth. However, it is not the correlation coefficient but its square which determines the overlap in the number of small causes which produce the dependence in question. When both variables, say $\mathrm{x}$ and $\mathrm{y}$, are assumed to be built up of simple elements of equal variability, it can be proved mathematically (Ezekiel, 1941) that $r^{2}$, the square of the correlation coefficient, means that proportion of the elements in $y$ which is also present in $x$. For that reason, in cases where the dependent variable is known to be causally related to the independent variable, $r^{2}$ is to be regarded as the coefficient of determination. To show the meaning of $\mathrm{r}^{2}$ in diagrammatic form (Fig. 1) let us assume that the area of each of the two circles represents the elements which go into the make-up of the variability of birth weights and subsequent weight. Their overlap then represents $r^{2}$.

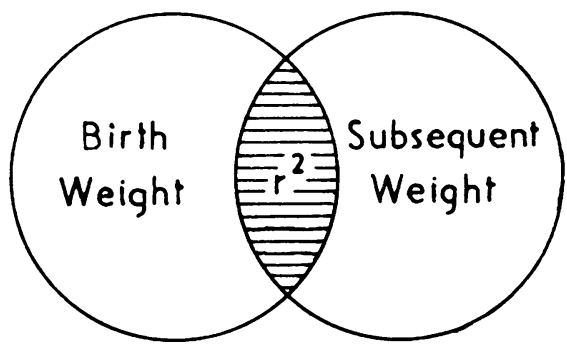

Diagram 1

The square of the correlation coefficient, $r^{2}$, represents the overlap of small causes which determine birth weight and subsequent weight

It may be said to measure the percentage to which the variance in $y$ is determined by $x$. Thus, in the given case, of the many causes which go into the make-up that determine subsequent weight, only $r^{2}=\cdot 25$ or $\frac{1}{4}$, is common to both variables (weights). That shows that the dependence is really a rather restricted, if not a weak, one. These conclusions are confirmed in a study on children's weights (Bayley and Davis, 1935) where, in a very careful study of growth changes in 61 children, the author arrived at a correlation coefficient of 40 between the series of birth weight and weight at 3 years of age. Since the random error of $r=.40$ is, in a sample of 61 individuals, approximately $0 \cdot 11$, this result is in good agreement with that reached by Lowe and Gibson, and we may, therefore, regard the range of the squares of $\mathrm{r}$, viz. $\frac{1}{4}$ to $\frac{1}{6}$ approximately, as a good estimate of the intensity of dependence between birth weight and the weight at three years. This means that from $75 \%$ to $83 \%$ of the variation of body weight at 3 years is determined by factors other than birth weight.

Bayley and Davis also remark about the comparatively weak connexion'between birth weight and weight at 3 years, which, according to them, is fourth in rank of the relations studied, viz., head circumference, length, stem-length (with $\mathrm{r}=\cdot 72, \cdot 68$ and .59 respectively). I have left out in this assessment the reduction which the correlation coefficient would have to suffer on account of its being obtained only from a sample and not from the population itself, but even so it shows to what a great extent the fundamental statement at the beginning of this paper must be qualified as regards the intensity of connexion between birth weight and subsequent weight. And this must be taken into account whenever one wishes to explain a child's subsequent weight by reference to its birth weight. The error of estimate for an individual observation is a function of $\mathrm{r}^{2}$; without going into mathematical detail, it may be sufficient to know that the smaller $\mathrm{r}^{2}$, the greater the error.

\section{Supposed Constant Relationship between Birth and Subsequent Weights}

The relationship between birth weight and subsequent weight was taken to be constant at all ages studied, that is, from 1 to 13 years, but mere inspection of the numerical tables (Table 1) shows the relationship as anything but constant. As is only to be expected, it diminishes with increasing age and it is quite clear why this must be so. In the earliest stages of life the body weight will exceed the birth weight only by a small amount and therefore differences in the latter will be of paramount importance in the body weight at these early stages of life. The more, on the other hand, that weight 
increases with age, the less important must the birth weight be as a constituent of the total weight, because it becomes relatively smaller and smaller compared with additional weight since birth. These conditions are fully confirmed by obtaining correlation coefficients for subsequent stages of life.

From a survey of the growth of babies in Bristol during 1951 (Table 2), correlation coefficients were calculated between birth weight and the weight at 13 weeks, and furthermore, between birth weight and the weight at 26 weeks.

TABLE 2

AVERAGE WEIGHT OF BRISTOL CHILDREN BORN IN 1951 AT 13 AND 26 WEEKS ACCORDING TO BIRTH WEIGHT CLASSES

\begin{tabular}{c|c|c}
\hline $\begin{array}{c}\text { Birth Weight } \\
\text { in lb. }\end{array}$ & $\begin{array}{c}\text { Average Weight } \\
\text { at } \begin{array}{c}13 \text { Weeks } \\
\text { (lb. oz.) }\end{array}\end{array}$ & $\begin{array}{c}\text { Average Weight } \\
\text { at 26 weeks } \\
\text { (lb. oz.) }\end{array}$ \\
\hline-4.5 & $9.59(1)^{*}$ & 14.28 (1) \\
-5.0 & $11.11(2)$ & 13.32 (2) \\
-5.5 & $11.50(15)$ & 17.25 (2) \\
-6.0 & $11.39(16)$ & $16.31(9)$ \\
-6.5 & $11.93(25)$ & $16.13(13)$ \\
-7.0 & $12.46(40)$ & $17.05(14)$ \\
-7.5 & $13.25(36)$ & $16.95(38)$ \\
-8.0 & $13.29(26)$ & $17.12(26)$ \\
-8.5 & $13.28(19)$ & $18.04(23)$ \\
-9.0 & $14.28(9)$ & $18.89(15)$ \\
-9.5 & $14.34(2)$ & $19.03(9)$ \\
-10.0 & $15.72(2)$ & $18.42(4)$ \\
-10.5 & $18.88(4)$
\end{tabular}

* The figures in parenthesis give the numbers of children in each weight class.

The correlation coefficients were $\cdot 56$ and $\cdot 44$ respectively. These results are in agreement with the considerations at the beginning of this section. The decrease of the correlation coefficient with age of the child is confirmed by Bayley and Davis who obtain a markedly higher correlation coefficient after 1 year of age than the figure they give in their paper for the relation at 3 years of age. Thus the dependence, such as it is, is not constant through childhood, but decreases systematically with age.

\section{Hypothetical Influence of Birth Weight upon Weight Gain}

The hypothesis of birth weight standing in an important relationship to subsequent weight does not imply, as might be thought, a continuous influence of the former upon the way a child grows. If correlation analysis is applied to such data almost the opposite is seen to be true. Lowe and Gibson have calculated the regression equation between birth weight ( $\mathrm{x}$ ) and weight at 3 years of age (y) as (roughly) $y=25 \cdot 3+x$ for males and $y=24 \cdot 6+x$ for females. This means in words that the excess of a child's weight over a constant weight gain roughly of $25 \mathrm{lb}$. is represented by the birth weight. This implies that no matter what the birth weight, a child will, on an average, gain $25 \mathrm{lb}$. in three years. If that is true, then clearly growth in terms of weight gain since birth is independent of birth weight. In other words the latter has no influence upon the way in which a child grows.

Although Lowe and Gibson's findings of a constant weight gain independent of birth weight are supported by another investigator (Parfit, 1951), yet the matter of growth seems too complex for us to abide completely by these conclusions unless they were supported by more material. It is very difficult to imagine that the factors which make for weight act in such a way as to make the weight increase constant for all children irrespective of their birth weight.

The investigation on babies' weights in Bristol mentioned above does, at any rate, not fully bear out such an assumption (Table 3).

If the weights at 3 and 6 months are examined, and the children divided into two groups, that is with birth weight up to $7 \mathrm{lb}$. and those with birth weight higher than $7 \mathrm{lb}$., it is found that the average weight increase is for the first group $5 \cdot 34 \mathrm{lb}$. and for the second group $5 \cdot 15 \mathrm{lb}$. Thus the increase seems to be in inverse relation to the average birth weight. At 6 months of age we find for the first group, that is for the lighter children, the average increase to be $10.02 \mathrm{lb}$. and for the heavier children $9 \cdot 50 \mathrm{lb}$.

TABLE 3

AVERAGE WEIGHT GAIN OF BRISTOL CHILDREN BORN IN 1951 AT 13 AND 26 WEEKS ACCORDING TO BIRTH $\%$ WEIGHT CLASSES

\begin{tabular}{|c|c|c|}
\hline $\begin{array}{c}\text { Weight at } \\
\text { Birth } \\
\text { (lb. oz.) }\end{array}$ & $\begin{array}{l}\text { A verage Weight } \\
\text { Gain at } 13 \text { Weeks } \\
\text { (lb. oz.) }\end{array}$ & $\begin{array}{c}\text { Average Weight } \\
\text { Gain at } 26 \text { Weeks } \\
\text { (lb. oz.) }\end{array}$ \\
\hline $\begin{array}{r}5 \cdot 9 \\
5 \cdot 0-5 \cdot 5 \\
5 \cdot 5-6 \cdot 0 \\
6 \cdot 0-6 \cdot 5 \\
6 \cdot 5-7 \cdot 0\end{array}$ & $\begin{array}{ll}4 \cdot 90 & (1)^{*} \\
5 \cdot 84 & (2) \\
5 \cdot 73 & (15) \\
5 \cdot 19 & (16) \\
5 \cdot 25 & (25)\end{array}$ & $\begin{array}{r}9.84 \\
8.63 \\
12.03 \\
10.12 \\
10.65 \quad(9) \\
9.90(13) \\
10.35(14)\end{array}$ \\
\hline $\begin{array}{r}7 \cdot 0-7 \cdot 5 \\
7 \cdot 5-8 \cdot 0 \\
8 \cdot 0-8 \cdot 5 \\
8 \cdot 5-9 \cdot 0 \\
9 \cdot 0-9 \cdot 5 \\
9 \cdot 5-10 \cdot 0 \\
10 \cdot 0-10 \cdot 5\end{array}$ & $\begin{array}{ll}5 \cdot 29 & (40) \\
5 \cdot 24 & (36) \\
5 \cdot 17 & (26) \\
4 \cdot 69 & (19) \\
5 \cdot 16 & (9) \\
4 \cdot 72 & (2) \\
5 \cdot 19 & (2)\end{array}$ & 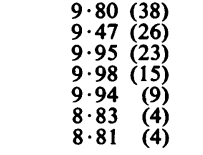 \\
\hline
\end{tabular}

* No. of children in each group.

The weight gain is thus again in inverse relation to the average birth weight. These results may be tabulated as follows.

AVERAGE WEIGHT GAIN OF CHILDREN BORN IN BRISTOL IN 1951 AT 13 AND 26 WEEKS ACCORDING TO TWO BIRTH IN 1951 AT 13 AND 26 WEEKS ACCOR

\begin{tabular}{c|c|c}
\hline Birth Weight & 13 Weeks & 26 Weeks \\
\hline \multicolumn{1}{c|}{$<7 \mathrm{lb}}$. & $5.34 \mathrm{lb}$. & $\begin{array}{r}10.02 \mathrm{lb} . \\
9.50 \mathrm{lb} .\end{array}$ \\
\hline $7 \mathrm{lb}$. & $5.15 \mathrm{lb}$. & \\
\hline
\end{tabular}


Without wishing to decide whether such reversal is sympathetic and must be expected, we may look upon it as an indication that the hypothesis of the weight increase as being entirely independent of the birth weight may not be correct, and that the influence of birth weight upon weight gain may even be the reverse of what the original hypothesis implied it to be. Another point which makes us suspect the hypothesis is the curious reversal which Lowe and Gibson have observed as regards the correlation between birth weight and birth order, and between subsequent weight and birth order, the first giving a positive correlation and the latter a negative correlation. It is clear that had the increase been the same throughout, the correlation would have remained positive. If, on the other hand, the increase had a systematic inverse trend with birth weight, then we should expect a reversal of this kind. However this may be, it looks as if the view of a complete independence of weight gain and birth weight was an over-simplification of the matter and that probably the relation, whatever it may be, changes with age.

\section{Summary}

(1) Birth weight exerts a definite, but rather restricted, influence upon subsequent weight. At 3 years of age it could be assessed as accounting for not more than $25 \%$ of the variation in subsequent weight.

(2) The relation between birth weight and subsequent weight is not constant but decreases systematically with the age of the child.

(3) The relation under (1) implies, as far as it goes, that 'growth', in terms of weight gain, is independent of the birth weight. This, however, is shown to be an over-simplification of the actual relationship.

\section{REFERENCES}

Bayley, N. and Davis, F. C. (1935). Biometrika, XXVII, 26. Ezekiel, M. J. B. (1941). Methods of Correlation Analysis, 2nd ed. New York.

Illingworth, R. S. (1950). Brit. med. J., 1, 96.

- Harvey, C. C. and Gin, S. Y. (1949). Lancet, 2, 598 Lowe, C. R. and Gibson, J. R. (1953). Brit. J. prev. soc. Med., 7, 78. Parfit, J. (1951). Brit. J. Soc. Med., 5, 1. 